\title{
Supplementary Information of
}

\section{DNA Binding of Tilorone; ${ }^{1} \mathrm{H}$ NMR and Calorimetric Studies of the Intercalation.}

Tomoki Nishimura, ${ }^{\S}$ Tadashi Okobira, ${ }^{\S}$ Andrew M. Kelly, ${ }^{\ddagger}$ Naohiko Shimada, ${ }^{\S}$ Yoichi Takeda, ${ }^{\S}$ and Kazuo Sakurai ${ }^{\S}$ *

$\S$ Department of Chemical Processes \& Environments, The University of Kitakyushu, 1-1 Hibikino, Wakamatu-ku, Kitakyushu, Fukuoka 808-0135, Japan ¥Department of Chemistry, University of Bath, Bath, BA2 7AY, U.K.

* Corresponding author

sakurai@env.kitakyu-u.ac.jp, Fax: +81-93-695-3390, Phone: +81-93-695-3298. 
S1 Viscosity measurements

Polyelectrolyte solutions show abnormal up-turn of the relative viscosity at low polymer concentrations when the electrostatic shielding is not enough (i.e., low salt concentration). This feature makes impossible to extrapolate the relative viscosity to infinite dilution. Figure S1A shows the salt concentration dependence of $\ln \eta_{r} / c$ vs $c$ plot. It can be seen that the extrapolation can be done when $[\mathrm{NaCl}]>0.5 \mathrm{mM}$. Figure S1B shows an example of the determination of $[\eta]$. In this case, $\mathrm{T} / \mathrm{B}=0.1$.
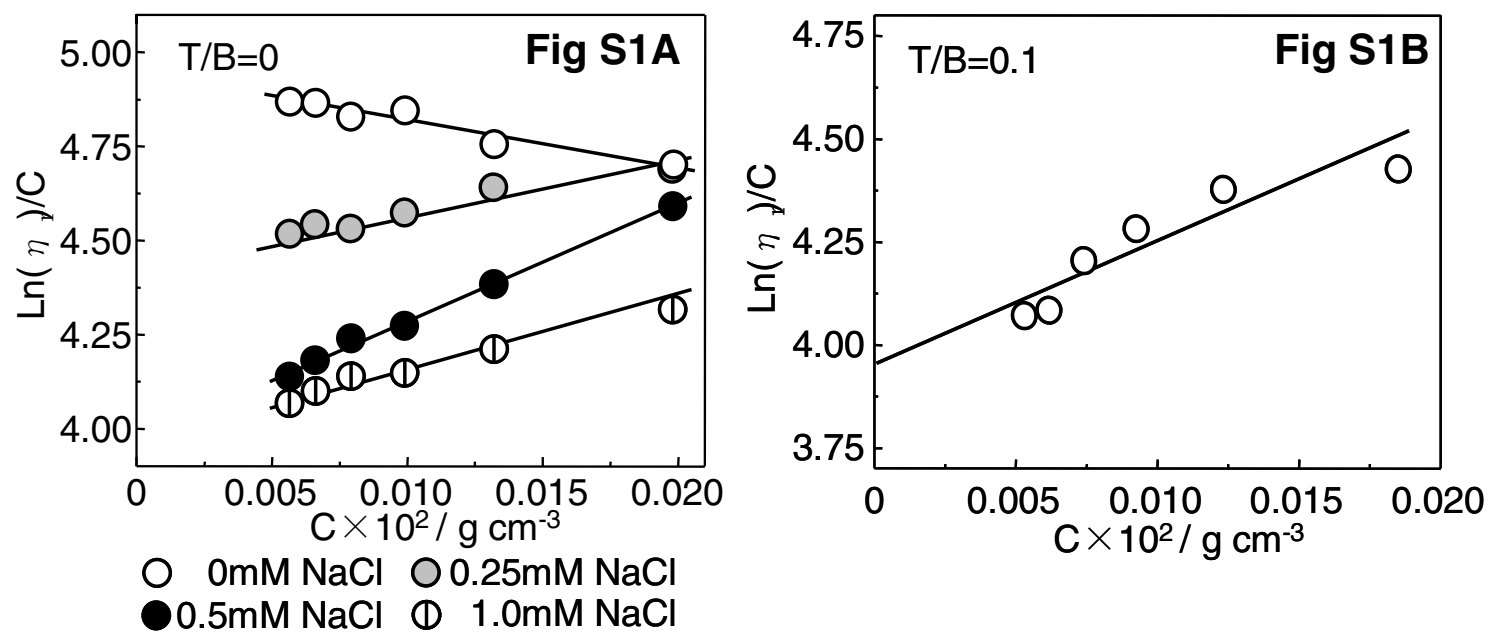
S2 CD spectral changes for $[\mathrm{NaCl}]=10 \mathrm{mM}$ and $20 \mathrm{mM}$

There was no upper limit in the $\mathrm{CD}$ spectral changes when $[\mathrm{NaCl}]=0$, as presented in Figure 5. On the other hand, there was upper limit observed when salts were present in the solution. Figure $\mathrm{S} 2$ show the $\mathrm{CD}$ changes when $[\mathrm{NaCl}]=10 \mathrm{mM}$ and $20 \mathrm{mM}$. The plots of Figure 6 were constructed from these spectra.
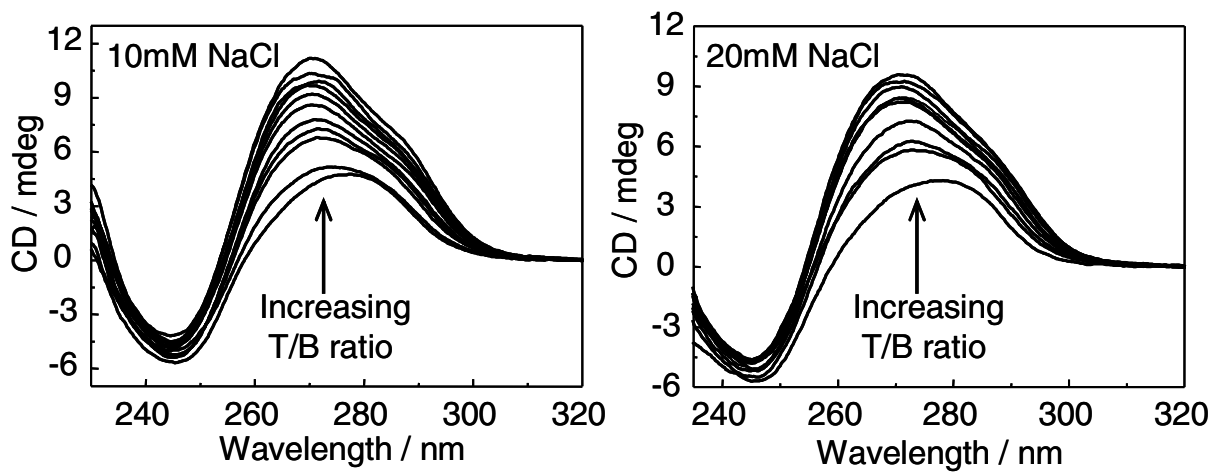
S3 CD spectral changes when tilorone was intercalated into AT or GC

In order to determine the melting temperature increment due to intercalation, we measured the CD changes for poly(dA)-poly(dT), poly(dC)-poly $(\mathrm{dG})$, poly $(\mathrm{dA}-\mathrm{dT})$, and poly $(\mathrm{dC}-\mathrm{dG})$ upon the tilorone intercalation.
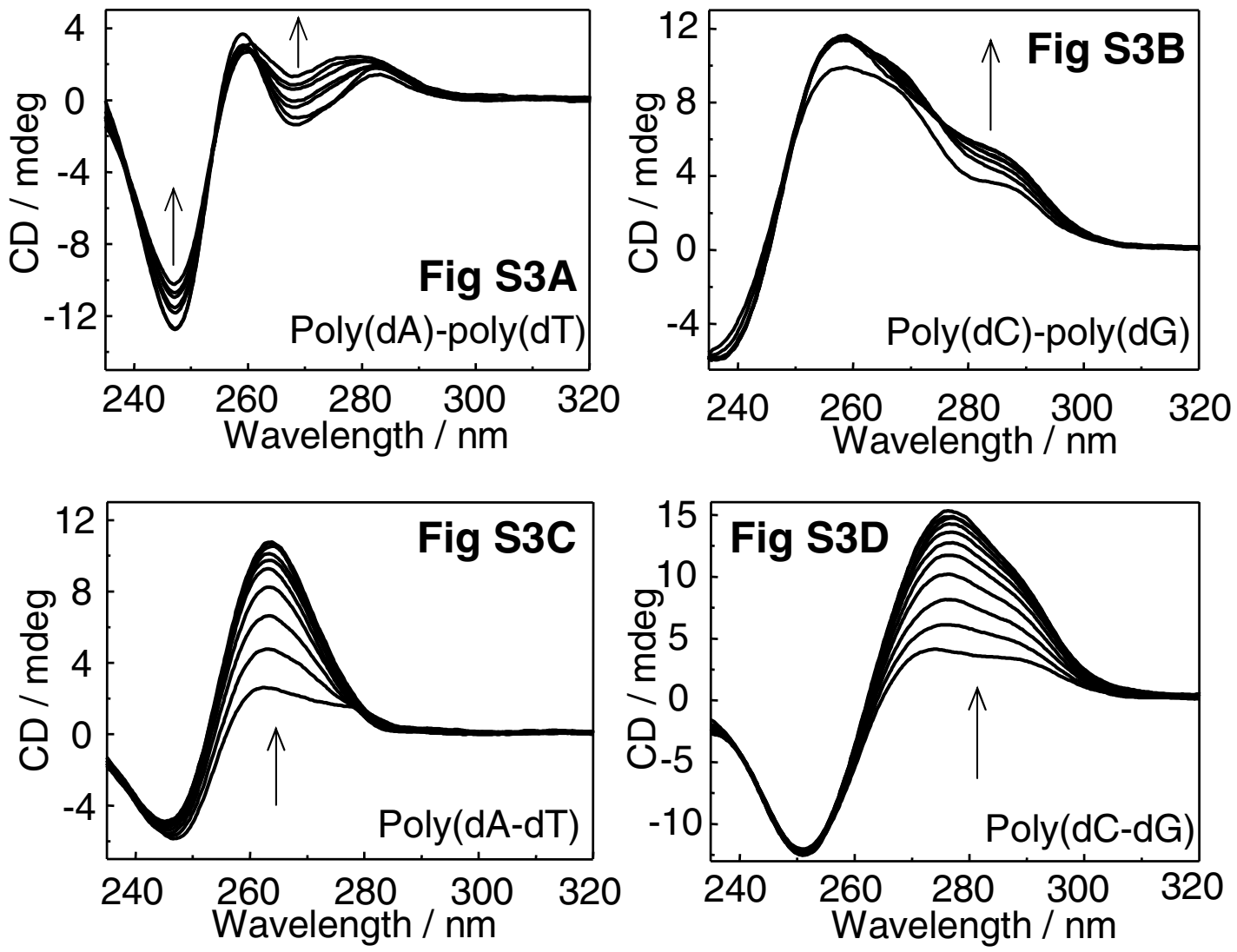
S4 Melting temperature increment due to intercalation

The melting temperature is increased with increasing $T / B$ similarly to other intercalators $(1)$.

Fig S4A

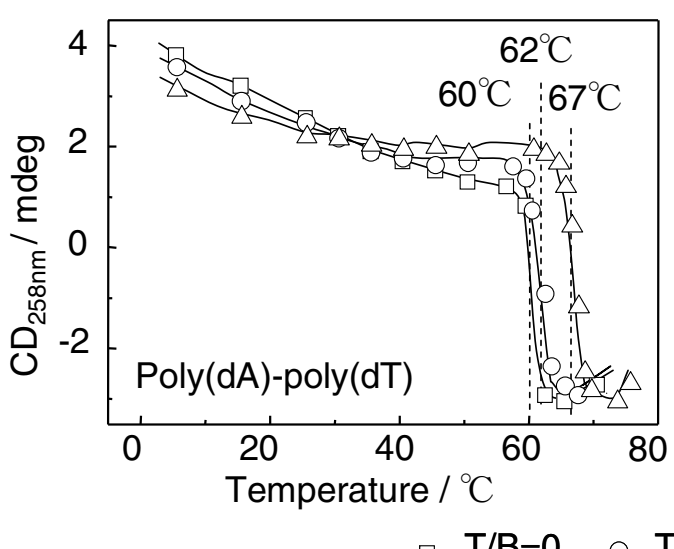

Fig S4B

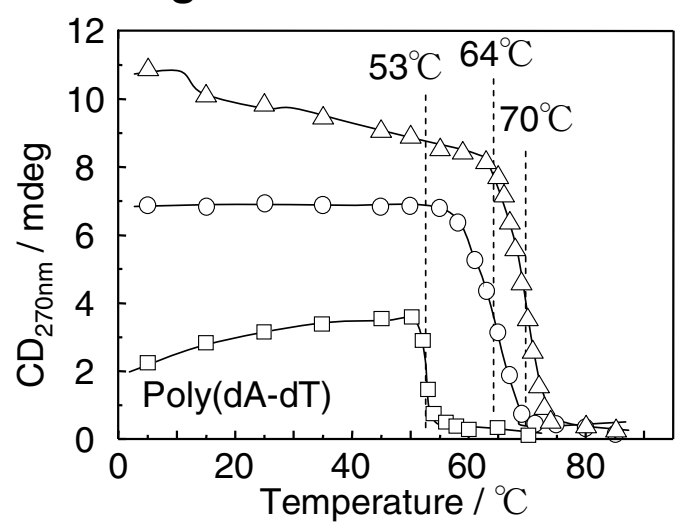

$\square \mathrm{T} / \mathrm{B}=0 \quad \circ \mathrm{T} / \mathrm{B}=0.1 \quad \triangle \mathrm{T} / \mathrm{B}=0.2$ 
S5 Comparison with EtBr

Figure S5A presents the thermogram for different $\mathrm{NaCl}$ concentrations and the solid lines are the best fit in terms of the one site or two sites model (see the text). The resultant parameters are summarized in Table $\mathrm{S} 2$.

When compared the value of $K_{b}$ between tilorone and EtBr, these are in the same magnitude. To confirm this fact, we added tilorone to the EtBr-intercalated DNA and measured the fluorescence intensity (Figure S5B). In this case, the fluorescence intensity is only caused by the intercalated EtBr. When tilorone was added at the equimol of $\mathrm{EtBr}(\mathrm{T} / \mathrm{E}=1)$, the fluorescence intensity decreased by almost $50 \%$. This is one of the strong evidence that tilorone has the same magnitude of $K_{b}$ as $\mathrm{EtBr}$.

Figure S5A

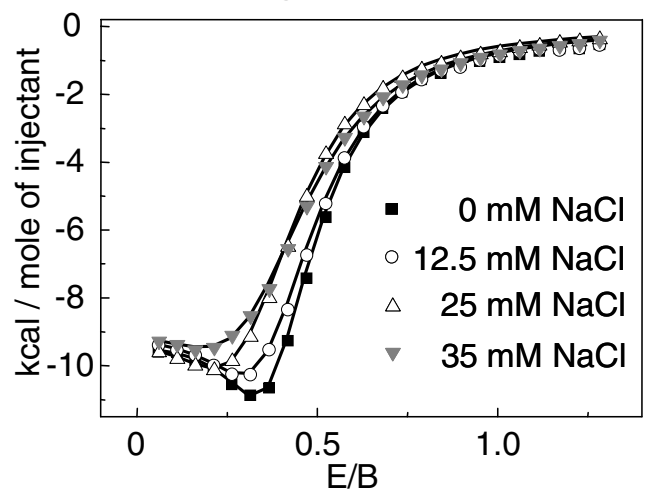

Figure S5B

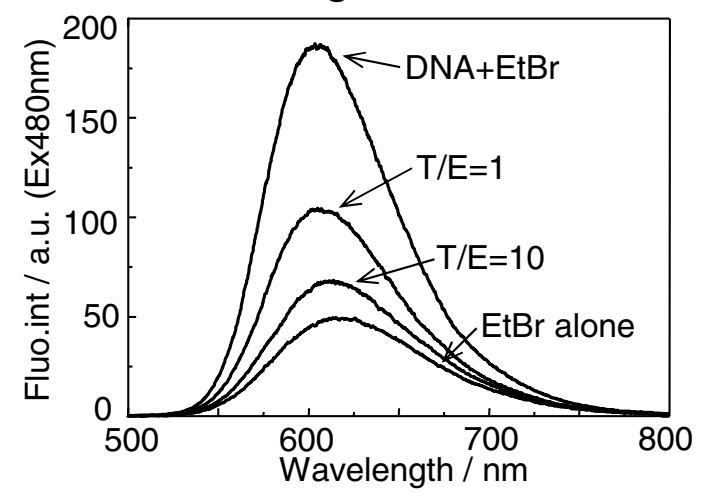


S6 NMR and Tm

For the sample used in NMR, direct measurement of Tm with CD was practically impossible owing to such a high concentration $(34.2 \mathrm{mM})$. We measured CD melting curves at three concentrations $(0.00525,0.0525$, and $0.525 \mathrm{mM})$ as presented in Fig 6A. From these data we evaluated Tm for each concentration and constructed the Arrhenius plot (Fig 6B). Three data points are fitted by a straight line and we estimated Tm at 34.2 $\mathrm{mM}$ (NMR concentration) to be $52{ }^{\circ} \mathrm{C}(325 \mathrm{~K})$. This value is higher than the temperate at which NMR was recoded.
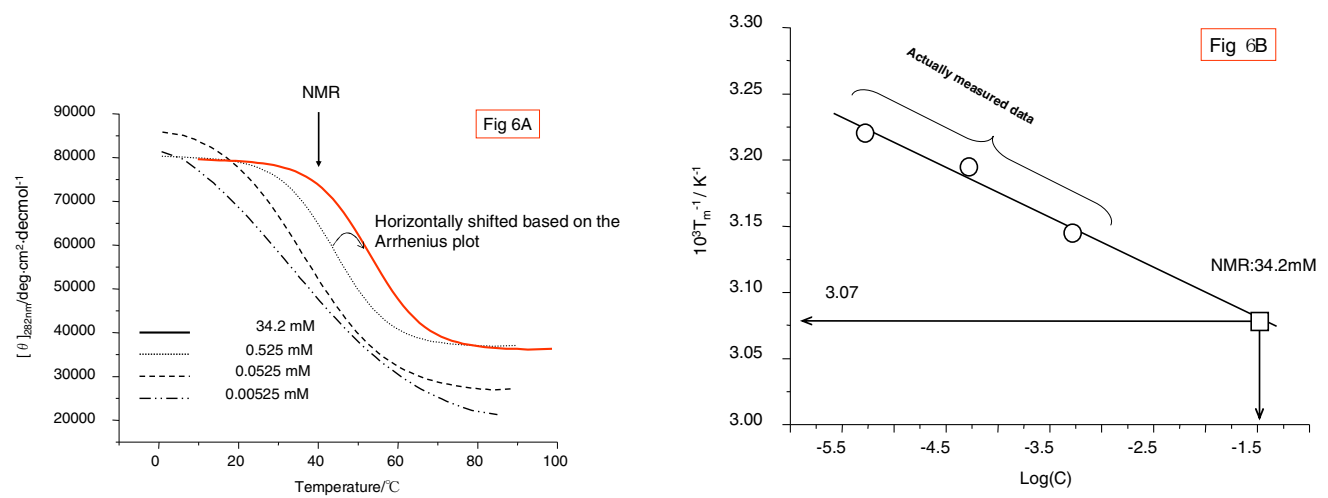

The red curve in Fig 6A presents the predicted melting curve at the concentration of $34.2 \mathrm{mM}$ (NMR) and our NMR measurement was carried out $41{ }^{\circ} \mathrm{C}$ (indicated by the arrow). It can be seen that the most base pairs are hybridized at the concentration and temperature that we used for NMR. 
S7 Molecular modeling

DNA conformation was constructed according to HyperChem (Ver 6.03) data base. Tilorone model was optimized with MOPAC AM1 and the resultant structure was inserted into AT/TA. After added $16 \mathrm{H}_{3} \mathrm{O}^{+}$ions as the counter of DNA phosphoric anions, MM3 (molecular mechanics) and then MOPAC AM1 were carried out to obtain the most stable structure (Fig 3).

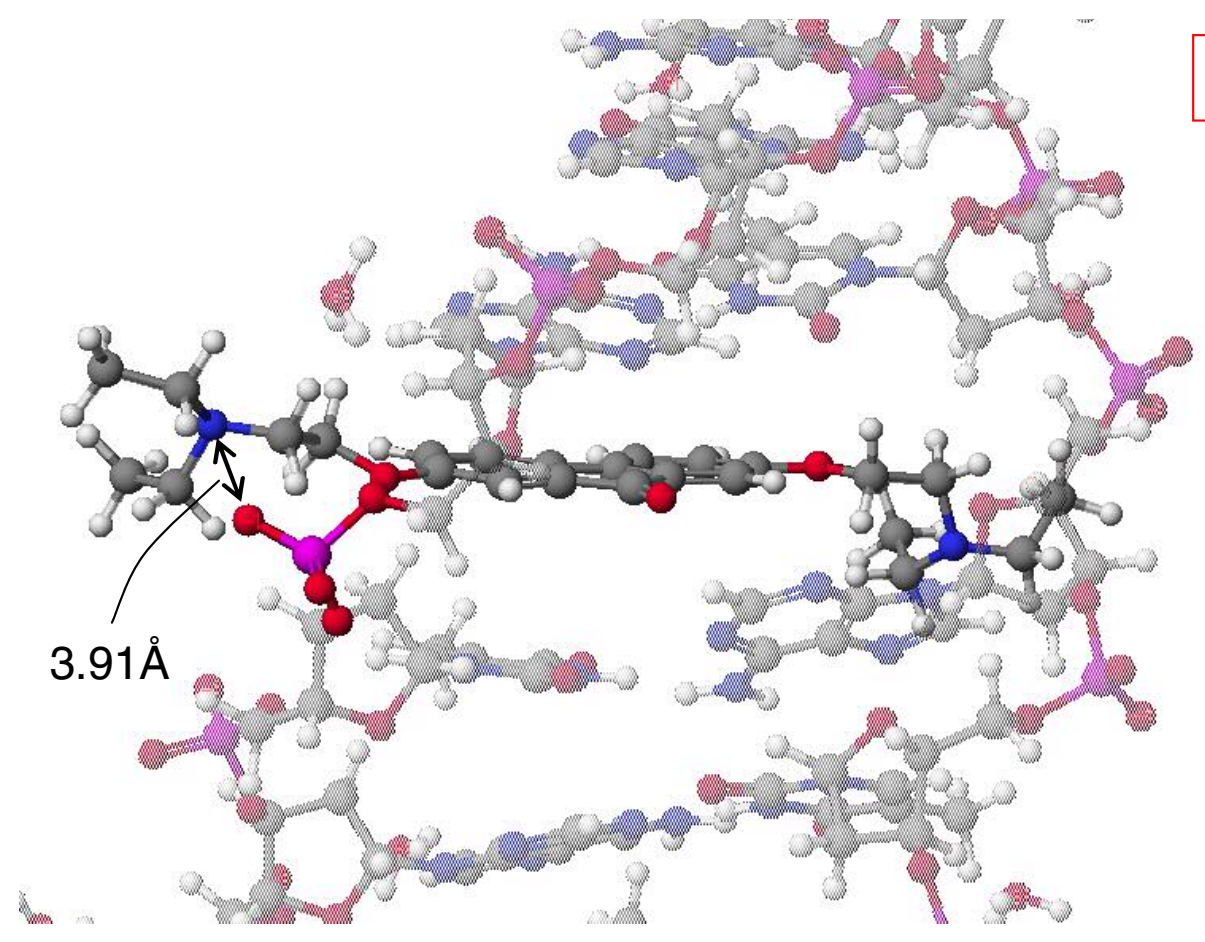

Fig S7

From this model, the distance between $\mathrm{O}$ and $\mathrm{N}$ was evaluated to be $3.9 \mathrm{~A}$. This distance is short enough to form an ionic interaction. 
Supplementary Tables

Table S1. ${ }^{1} \mathrm{H}$ Chemical Shift assignments (ppm) for DNA

\begin{tabular}{ccccccccc}
\hline Nucleoside & $\mathrm{H} 8 / \mathrm{H} 6$ & $\mathrm{H}^{\prime} / \mathrm{CH}_{3} / \mathrm{H} 2$ & $\mathrm{H} 1^{\prime}$ & $\mathrm{H} 2^{\prime}$ & $\mathrm{H} 2^{\prime \prime}$ & $\mathrm{H}^{\prime}$ & $\mathrm{H}^{\prime}$ & $\mathrm{H}^{\prime} / \mathrm{H} 5^{\prime \prime}$ \\
\hline G1 & 7.984 & -- & 5.874 & 2.243 & 2.683 & 4.876 & 4.263 & 3.769 \\
C2 & 7.573 & 5.493 & 6.137 & 2.166 & 2.535 & 4.830 & 4.285 & 4.107 \\
T3 & 7.439 & 1.754 & 6.037 & 2.683 & 2.777 & 4.876 & 4.208 & 4.083 \\
A4 & 8.338 & n.a. ${ }^{\mathrm{a}}$ & 6.256 & 2.683 & 2.807 & 4.994 & 4.353 & n.a. \\
T5 & 7.185 & 1.526 & 5.638 & 2.243 & 2.243 & 4.830 & 4.107 & n.a. \\
A6 & 8.153 & n.a. & 6.024 & 2.683 & 2.807 & 4.994 & 4.402 & 4.172 \\
G7 & 7.727 & -- & 5.874 & 2.166 & 2.618 & 4.953 & 4.353 & 4.208 \\
C8 & 7.439 & 5.493 & 6.202 & 2.535 & 2.535 & 4.497 & 4.083 & n.a. \\
\hline
\end{tabular}

${ }^{a}$ Not assigned. 
Table S2. Thermodynamic Parameters for the Association of EtBr with DNA at Different Salt Concentration

\begin{tabular}{cccccc}
\hline$\left[\mathrm{Na}^{+}\right] / \mathrm{mM}$ & $\Delta H_{1} / \mathrm{kcalmol}^{-1}$ & $T \Delta S_{1} / \mathrm{kcalmol}^{-1}$ & $\Delta G_{1} / \mathrm{kcalmol}^{-1}$ & $K_{b 1} \times 10^{5} / \mathrm{M}^{-1}$ & $n_{1}$ \\
\hline 0 & -9.27 & -0.66 & -8.59 & 20.4 & 0.32 \\
12.5 & -9.04 & -0.58 & -8.45 & 16.0 & 0.29 \\
25 & -9.17 & -0.69 & -8.46 & 16.4 & 0.21 \\
35 & -8.84 & -0.59 & -8.23 & 11.1 & 0.21 \\
\hline$\left[\mathrm{Na}^{+}\right] / \mathrm{mM}$ & $\Delta H_{2} / \mathrm{kcalmol}^{-1}$ & $T \Delta S_{2} / \mathrm{kcalmol}^{-1}$ & $\Delta G_{2} / \mathrm{kcalmol}^{-1}$ & $K_{b 2} \times 10^{5} / \mathrm{M}^{-1}$ & $n_{2}$ \\
\hline 0 & -32.54 & -25.72 & -6.80 & 0.99 & 0.11 \\
12.5 & -23.99 & -17.14 & -6.84 & 1.06 & 0.14 \\
25 & -17.38 & -10.37 & -6.97 & 1.32 & 0.20 \\
35 & -16.62 & -9.69 & -6.91 & 1.20 & 0.21 \\
\hline
\end{tabular}


Table S3 Thermodynamic parameters for the first binding between Tilorone and sss-DNA.

\begin{tabular}{cccccc}
\hline$\left[\mathrm{Na}^{+}\right] / \mathrm{mM}$ & $\Delta H_{1} / \mathrm{kcalmol}^{-1}$ & $T \Delta S_{1} / \mathrm{kcalmol}^{-1}$ & $\Delta G_{1} / \mathrm{kcalmol}^{-1}$ & $K_{b 1} \times 10^{6} / \mathrm{M}^{-1}$ & $n_{1}$ \\
\hline 0 & -4.14 & 5.30 & -9.49 & 8.60 & 0.08 \\
10 & -4.46 & 4.83 & -9.25 & 6.26 & 0.07 \\
20 & -4.50 & 7.12 & -8.87 & 3.26 & 0.03 \\
\hline
\end{tabular}


<smiles>[NH3+]CCCCCCCCNCc1c2ccccc2cc2ccccc12</smiles>

anthracene derivative<smiles></smiles>

dppz derivative

Table S4. Thermodynamic Parameters for the Binding of anthracene derivative and dppz derivative

\begin{tabular}{cccccc}
\hline Ligand & $\Delta H / \mathrm{kcalmol}^{-1}$ & $T \Delta S / \mathrm{kcalmol}^{-1}$ & $\Delta G / \mathrm{kcalmol}^{-1}$ & $K_{b} \times 10^{4} / \mathrm{M}^{-1}$ & $n$ \\
\hline $\begin{array}{c}\text { anthracene } \\
\text { derivative } \\
\begin{array}{c}\text { dppz } \\
\text { derivative }\end{array}\end{array}$ & -4.1 & 3.6 & -7.7 & 40.0 & 0.260 \\
\hline
\end{tabular}




\section{References}

(1) Ihtshamul, H., John, E. L., Babur, Z. C., and Terence, C. J. (1996) Molecular Anchoring of Duplex and Triplex DNA by Disubstituted Anthracene-9,10-diones:

Calorimetric, UV Melting, and Competition Dialysis Studies. J. Am. Chem. Soc. 118, 10693-10701. 